\title{
Motor competence deficit in urban-area Brazilian children based on chronological age
}

\author{
ERIC L. AVIGO'| DAVID F. STODDEN² | AYRTON A. R. DA SILVA'| VINICIUS B. RODRIGUES' | JOSÉ A. BARELA|
}

1 Institute of Physical Activity and Sport Science, Cruzeiro do Sul University, São Paulo, SP, BRAZIL

2 Department of Physical Education and Athletic Training, Blatt Physical Education Center, University of South Carolina, USA

3 Institute of Biosciences, São Paulo State University, Rio Claro, SP, BRAZIL

Correspondence to: José A. Barela, Institute of Bioscience, São Paulo State University, 13506-00, BRAZIL.

email: jose.barela@unesp.br

https://doi.org/10.20338/bjmb.v13i2.128

\begin{abstract}
HIGHLIGHTS
- Children from São Paulo city show low competence levels of fundamental motor skills.

- Motor competence deficit in São Paulo city children increases with chronological age.

- São Paulo city children's competence levels were classified as poor and very poor.
\end{abstract}

\section{ABBREVIATIONS \\ BMI body mass index \\ FMS fundamental motor skills \\ MANOVA multivariate analysis of variance \\ TGMD-2 Test of Gross Motor Development- Second Edition \\ USA United States of America}

PUBLICATION DATA

Received 18 Feb 2019

Accepted 10 May 2019

Published 01 Aug 2019
BACKGROUND: Previous studies have confirmed, based on various samples, that there is a developmental delay in the fundamental motor skills (FMS) of Brazilian children. However, none of these studies included a comprehensive and direct diagnosis of motor competence levels of children in the urban areas of Brazil, which tend to encompass a wide range of socioeconomic and cultural environments.

AIM: The purpose of this study was to directly assess children's FMS competence levels in the city of São Paulo, Brazil.

METHOD: Three hundred and eighty-three children (ages 6, 8, and 10) from elementary schools in all five geographic regions of São Paulo participated in this study. The FMS of the children were assessed using the Test of Gross Motor Development-Second Edition.

RESULTS: The results indicated that children from all five geographic areas of São Paulo demonstrated low competence levels (below the $15^{\text {th }}$ percentile) across all FMS. Moreover, the observed motor competence deficit increased with age. Children's competence levels were classified as poor in 6-year-old children and very poor in 8- and 10-year-old children.

CONCLUSION: The developmental delay in motor competence is associated with decreased levels of healthenhancing physical activity, physical fitness, executive function, and perceived competence, as well as increased obesity.

KEYWORDS: Fundamental motor skills (FMS) | motor competence | developmental delay | elementary school children| Test of Gross Motor Development-Second Edition (TGMD-2)

\section{INTRODUCTION}

Since healthy behavior habits are formed during childhood, the acquisition of motor competence in a child's first 10 years of life is critical ${ }^{1}$. In addition, the development of wide-ranging fundamental motor skills (FMS) provides a strong foundation that influences a person's motor experiences throughout their lifespan ${ }^{2}$. However, the development of high levels of motor competence is the result of a long journey that involves, among other aspects, high amounts of intentional practice ${ }^{3}$.

Newell's constraints model suggests that motor skill acquisition occurs based on the interaction of organismic, environmental, and task constraints ${ }^{4}$, indicating that motor skill development often requires specific environmental conditions which provide adequate and structured practice and instruction. Children's daily activities can often provide the necessary environmental conditions to naturally develop select motor skills; however, FMS competence does not emerge naturally ${ }^{5}$. Instead, FMS competence requires structured practice and specific instructions ${ }^{3,6}$.

Motor competence plays a major role in motor activity participation. Children and adolescents who are more motor competent are more engaged in physical activities due to their increased satisfaction and pleasure derived from these experiences ${ }^{7,8}$. Moreover, if a

\begin{tabular}{l|l|l|l|ll}
\hline Avigo et al. & 2019 & VOL.13 & N.2 & https://doi.org/10.20338/bjmb.v13i2.128
\end{tabular}


certain level of FMS competence is not achieved in early childhood, the development of future motor skills will be hampered in children 5, 9. Fundamental motor skills are considered the basis for more complex and specific activities that allow participation in a variety of structured popular games and sports ${ }^{3}$. Decreased motor activity participation leads to fewer physical activity opportunities 1, which in turn negatively affects the development of physical fitness ${ }^{10}$, promotes increased sedentary behaviors ${ }^{11}$, and results in unhealthy weight gain 12.

Based on different regional samples, several previous studies have indirectly confirmed that Brazilian children show low levels of FMS competence ${ }^{6,13,14}$. Each of these studies was based on relatively small samples of children.

To overcome this shortcoming, ${ }^{15}$ used a larger sample of Brazilian children (ages 3-10) from the city of Porto Alegre to examine FMS competence relative to expected levels. Based on the Test of Gross Motor Development ${ }^{16}$, the majority of boys (69\%) and girls $(82 \%)$ in the sample scored below the expected competence norms, and only a small percentage of boys $(23 \%)$ and girls $(15 \%)$ demonstrated average performance ${ }^{15}$. These authors speculated that the low motor competence observed in this sample may be attributable to the lack of formal physical education training for participating teachers or the lack of a physical education structure for elementary school children (physical education often comprises free-play activities rather than structured motor skill instruction) ${ }^{15}$.

The consistency with which these previous studies reported a lag in FMS competence for Brazilian children is concerning and suggests a need for further direct and comprehensive study. The purpose of this study was to directly assess FMS competence levels for children (ages 6, 8, and 10) from the city of São Paulo, Brazil-an urban area encompassing a wide range of socioeconomic and cultural environments. By pursuing this goal, we aimed to better understand the motor competence of Brazilian children and suggest potential factors affecting FMS competence levels.

\section{METHODS}

\section{Participants}

The sample for this study comprised 383 children (187 boys and 196 girls) enrolled in seven public elementary schools in the city of São Paulo, Brazil. We chose participants who were 6,8 , and 10 years old to reflect the age at which children start, are midway through, and finish elementary school, respectively. The sample size was based on the approximate public elementary school population in each of the São Paulo regions. Table 1 details the sample distribution of the Brazilian children who participated in the study.

Table 1 - Sample Distribution of Brazilian Children Participants

\begin{tabular}{lllllll}
\hline São Paulo & Approximate Public School & \multicolumn{3}{l}{ Participating Children by Age Group } & & Participating Schools \\
\cline { 2 - 6 } Regions & Population & 6 & 8 & 10 & Total & \\
\hline North & 52,249 & 29 & 16 & 19 & 64 & 1 \\
South & 106,095 & 38 & 34 & 34 & 106 & 2 \\
Downtown & 23,507 & 6 & 18 & 9 & 33 & 1 \\
East & 119,060 & 40 & 43 & 58 & 141 & 3 \\
West & 18,503 & 12 & 11 & 16 & 39 & 1 \\
Total & 319,414 & 125 & 122 & 136 & 383 & 8 \\
\hline
\end{tabular}

Note: Data were provided by the State Department of Education of São Paulo (2014).

Each school provided authorization to recruit participants. Children were randomly selected according to gender, age, and enrollment year (first-fifth grade). Participating

\begin{tabular}{l|l|l|l|ll}
\hline Avigo et al. & 2019 & VOL.13 & N.2 & https://doi.org/10.20338/bjmb.v13i2.128
\end{tabular}


children and their parents provided consent prior to data collection and the Institutional Ethics Committee approved the study procedures.

\section{Procedures}

Data were collected in the physical education facility (gymnasium or sport court) of each school. First, descriptive information including the birth date, hand and foot preference, body mass, and height of each child was obtained. To reliably assess motor competence, each child was videotaped performing the six locomotor skills (run, gallop, hop, leap, horizontal jump, and slide) and six object-control skills (striking a stationary ball, stationary dribble, kick, catch, overarm throw, and underarm roll) included in the normreferenced Test of Gross Motor Development-Second Edition (TGMD-2) ${ }^{16}$. The video camera arrangement and procedures used in this study were based on previous studies 6 , 14.

The TGMD-2 was administered by a team of trained researchers who followed the standard testing procedures ${ }^{16}$. Each child completed the test in approximately $15 \mathrm{~min}$, performing at least three trials for each gross motor skill-one practice trial and two valid trials for further analysis.

\section{Data Analysis}

After data collection, two trained evaluators independently analyzed each child's valid trials for each motor skill performed to determine a corresponding score based on the TGMD-2 performance criteria ${ }^{16}$. If a child's performance successfully met the TGMD-2 performance criterion, the scores of both trials were summed to obtain a raw score for each skill. If the two evaluators did not agree whether a child's performance successfully met the TGMD-2 performance criterion, a third evaluator made the decision. A concordance agreement among the evaluators specified the minimum acceptance as no less than 0.85 .

The six locomotor and six object-control skill scores were summed to provide an overall score, which was then converted to the motor age equivalent, percentile score, and standardized score for age and sex ${ }^{16}$. The motor age equivalent indicates the approximate age corresponding to the child's performance. The percentiles represent the percentage of children according to their age peers. The sum of the standardized score for each subtest can be used to determine the gross motor quotient. This latter parameter is suggested to be the most consistent TGMD-2 score as it reflects the combined performance in both subtests and thus represents the best estimate of a child's gross motor proficiency ${ }^{16}$. The gross motor quotient also supports the descriptive classification of child motor development as very poor, poor, below average, average, above average, superior, and very superior.

\section{Statistical Analysis}

After testing the assumptions for data normality (Shapiro-Wilk test) and homogeneity of variance (Levene test), statistical analyses were performed using multivariate analysis of variance (MANOVA) and paired t-test methods. Specifically, a twoway MANOVA with age $(6,8$, and 10$)$ and gender (male and female) factors was used to compare the anthropometric measures of body mass, height, and body mass index (BMI) among the children. Two additional two-way MANOVAs with age and gender factors were used to compare the raw scores and equivalent motor ages for the locomotor and object-

\begin{tabular}{l|l|l|l|ll}
\hline Avigo et al. & 2019 & VOL.13 & N.2 & https://doi.org/10.20338/bjmb.v13i2.128
\end{tabular}


control subtests. Supplemental paired t-tests were used to compare the equivalent motor ages for each subtest with the respective chronological age group. Two-way MANOVAs with age and gender factors were also used to compare the age difference (chronological age-equivalent motor age) and percentiles for each subtest.

When necessary, univariate analyses and post hoc tests with the Bonferroni adjustment were used. All analyses were performed using the SPSS Statistics software package (version 20) with a constant significance level of 0.05 .

\section{RESULTS}

\section{Anthropometric characteristics by age group}

Table 2 details the anthropometric characteristics (body mass, height, and BMI) by age group for the sample of children from São Paulo, Brazil at the time of testing. The twoway MANOVA confirmed an age group effect, Wilks' Lambda $=0.440, F(6,702)=59.43$, $p<0.001$. Univariate analyses confirmed differences among age groups for body weight, $F(2,353)=66.72, p<0.001$, height, $F(2,353)=215.78, p<0.001$, and $B M I, F(2,353)=11.95$, $p<0.001$. Post hoc tests confirmed that 10 -year-old children were heavier, taller, and had higher BMI values than 8- and 6-year-old children, and 8-year-old children were heavier, taller, and had higher BMI values than 6-year-old children.

Table 2 - Sample Mean (Standard Deviation) of Body Mass, Height, and Body Mass Index (BMI) by Age Group

\begin{tabular}{lllll}
\hline Age Group & $\begin{array}{l}\text { Chronological Age } \\
(\mathrm{yr})\end{array}$ & $\begin{array}{l}\text { Body Mass } \\
(\mathrm{kg})\end{array}$ & $\begin{array}{l}\text { Height } \\
(\mathrm{m})\end{array}$ & $\begin{array}{l}\text { BMl } \\
\left(\mathrm{kg} / \mathrm{m}^{2}\right)\end{array}$ \\
\hline 6 & $6.73(0.16)$ & $24.7(4.97)$ & $1.20(0,05)$ & $16.9(2.55)$ \\
8 & $8.64(0.26)$ & $31.1(7.77)$ & $1.31(0,06)$ & $17.8(3.24)$ \\
10 & $10.62(0.32)$ & $40.6(10.01)$ & $1.42(0.06)$ & $19.8(4.14)$ \\
\hline
\end{tabular}

Raw TGMD-2 scores, equivalent motor ages, and percentiles by age group and gender

Table 3 details the results of the TGMD-2 including the raw scores from the valid trials, equivalent motor ages, and percentiles for both the locomotor and object-control subtests, organized by age group and gender. Note that all participating children were able to perform the tasks of both subtests.

Considering first the results related to the raw scores and equivalent motor ages, the two-way MANOVA confirmed an age group effect for raw score and equivalent motor age in the locomotor subtest, Wilks' Lambda $=0.955, F(4,704)=4.137, p<0.005$. Univariate analyses confirmed differences among age groups for raw score, $F(2,353)=6.61, p<0.005$, and equivalent motor age, $F(2,353)=7.54$, $p<0.005$. For both of these variables, post hoc tests confirmed that 10 -year-old children had higher raw scores and equivalent motor ages than 8- and 6-year-old children.

Regarding the object-control subtest, the two-way MANOVA revealed both an age group effect, Wilks' Lambda $=0.828, F(4,704)=17.39$, $p<0.001$, and a gender effect, Wilks' Lambda $=0.367, F(2,352)=303.18, p<0.001$. Univariate analyses confirmed differences among age groups for raw score, $F(2,353)=35.61, p<0.001$, and equivalent motor age, $F(2,353)=31.51, p<0.001$. For both of these variables, post hoc tests confirmed that 10 year-old children had higher raw scores and equivalent motor ages than 8- and 6-year-old children, and 8-year-old children had higher raw scores and equivalent motor ages than 6year-old children. Univariate analyses confirmed differences by gender only for raw score, 
$F(1,353)=38.54, p<0.001$; boys had higher raw scores than girls. Independent of age group or sex, paired t-tests showed that the equivalent motor age was lower than the respective chronological age group in both the locomotor and object-control subtests $(p<0.001)$.

Considering the difference between chronological age and equivalent motor age, a two-way MANOVA revealed both age group effects, Wilks' Lambda $=0.167$, $F(4,752)=272.11, p<0.001$, and sex effects, Wilks' Lambda $=0.979, F(2,376)=4.02, p<0.05$. Univariate analyses confirmed differences between age groups in both the locomotor subtest, $F(2,377)=906.30, p<0.001$, and the object-control subtest, $F(2,377)=169.74$, $p<0.001$. For both subtests, post hoc tests showed that 10 -year-old children had a higher chronological-equivalent motor age difference than 8- and 6-year-old children, and 8-yearold children had a higher chronological-equivalent motor age difference than 6-year-old children. Univariate analyses confirmed differences by sex only for the object-control subtest, $F(1,377)=6.98, p<0.05$; boys had a higher chronological-equivalent motor age difference than girls.

Finally, considering the percentiles, the two-way MANOVA revealed an age group effect, Wilks' Lambda $=0.755, F(4,704)=26.58, p<0.001$. Univariate analyses confirmed differences between age groups for both the locomotor subtest, $F(2,353)=53.93, p<0.001$, and the object-control subtest, $F(2,353)=9.32, p<0.001$. For both subtests, post hoc tests showed that 6 -year-old children had higher percentile values than 8- and 10-year-old children.

Table 3 - Sample Mean (Standard Deviation) of Raw Score, Equivalent Motor Age, and Percentile for Locomotor and Objectcontrol Subtests by Age Group and Gender

\begin{tabular}{|c|c|c|c|c|}
\hline \multicolumn{5}{|l|}{ Locomotor Skills } \\
\hline \multirow[b]{2}{*}{ Raw Score } & 6 & $27.59(3.36)$ & $27.67(4.31)$ & $27.63(3.86)$ \\
\hline & 8 & $28.09(3.24)$ & $27.41(4.13)$ & $\begin{array}{l}27.77(3.69) \\
29.09(3.82)^{*}\end{array}$ \\
\hline \multirow{3}{*}{ Motor Age Equivalent } & 10 & $\begin{array}{l}28.54(3.84) \\
4.47(0.58)\end{array}$ & $\begin{array}{l}29.69(3.74) \\
4.49(0.72)\end{array}$ & $\begin{array}{l}29.09(3.82)^{x} \\
4.48(0.66)\end{array}$ \\
\hline & 8 & $4.56(0.56)$ & $4.47(0.60)$ & $4.52(0.58)$ \\
\hline & 10 & $4.66(0.66)$ & $4.83(0.66)$ & $4.74(0.66)^{\star}$ \\
\hline \multirow{3}{*}{ Percentile } & 6 & $10.13(5.47)$ & $11.29(9.23)$ & $10.72(7.62)^{\star}$ \\
\hline & 8 & $2.50(1.91)$ & $2.17(1.79)$ & $2.34(1.86)$ \\
\hline & 10 & $2.18(2.33)$ & $2.33(2.05)$ & $2.25(2.20)$ \\
\hline \multicolumn{5}{|l|}{ Object-control Skills } \\
\hline & Age Group & Girls & Boys & Total \\
\hline \multirow{4}{*}{ Raw score } & 6 & 26.54 (5.36) & $29.18(5.86)$ & $27.45(6.12)^{\star}$ \\
\hline & 8 & $30.00(4.38)$ & $33.39(5.35)$ & $31.61(5.14)^{*}$ \\
\hline & 10 & $32.09(4.88)$ & $36.36(4.00)$ & $34.13(4.95)^{\star}$ \\
\hline & Total & $29.68(5.37)$ & $32.98(5.91)^{\star \star}$ & \\
\hline \multirow{3}{*}{ Motor Age Equivalent } & 6 & $5.37(1.27)$ & $5.01(1.00)$ & $5.19(1.15)^{\star}$ \\
\hline & 8 & $6.10(1.09)$ & $5.76(1.03)$ & $5.94(1.07)^{*}$ \\
\hline & 10 & $6.60(1.19)$ & $6.40(1.09)$ & $6.51(1.14)^{*}$ \\
\hline \multirow{3}{*}{ Percentile } & 6 & $25.42(22.27)$ & $16.48(12.32)$ & $20.84(18.37)^{*}$ \\
\hline & 8 & $13.37(13.56)$ & $7.74(8.45)$ & $10.69(11.72)$ \\
\hline & 10 & $10.05(8.53)$ & 9.27 (12.05) & $9.68(10.33)$ \\
\hline
\end{tabular}

Notes: * indicates statically significant group difference from the others.

${ }^{* *}$ indicates statically significant gender difference.

Percentile frequencies and comparative São Paulo/normative TGMD-2 (USA) raw scores by age group and sex 
Table 4 details the TGMD-2 percentile frequencies by age group as well as the comparative raw scores for this study's sample of Brazilian children from São Paulo and the corresponding normative TGMD-2 values from the United States of America (USA) by age group and sex.

The percentile frequencies consistently showed higher concentrations of São Paulo children in the lower percentiles across all age groups. The highest frequencies of 6 year-old children were concentrated below the $20^{\text {th }}$ percentile in the locomotor subtest and below the $40^{\text {th }}$ percentile in the object-control subtest. Comparatively, the highest frequencies of 8 - and 10 -year-old children were concentrated below the $5^{\text {th }}$ percentile in the locomotor subtest and below the $20^{\text {th }}$ percentile for the object-control subtest.

Table 4 - Sample Percentile Frequencies and Comparative São Paulo/Normative (USA) Raw Scores for Locomotor and Objectcontrol Subtests by Age Group and Gender

\begin{tabular}{|c|c|c|c|c|c|c|c|c|c|}
\hline \multirow{2}{*}{$\begin{array}{l}\text { Age } \\
\text { Group }\end{array}$} & \multicolumn{5}{|c|}{ Percentile Frequency (\%) } & \multicolumn{4}{|c|}{ Raw Score } \\
\hline & $<5$ & 5 & $9-16$ & $25-37$ & $>50$ & São $P$ & & \multicolumn{2}{|c|}{ Normative (USA) } \\
\hline 6 & 9.6 & 25.6 & 56.0 & 8.8 & - & $24-28$ & & \multicolumn{2}{|c|}{$38-41$} \\
\hline 8 & 79.5 & 17.2 & 3.3 & - & - & $26-29$ & & \multicolumn{2}{|l|}{43} \\
\hline 10 & 80.2 & 16.2 & 3.6 & - & - & $28-31$ & & \multicolumn{2}{|l|}{44} \\
\hline Total & 56.9 & 19.7 & 20.6 & 2.8 & - & 24-31 & & \multicolumn{2}{|l|}{$38-44$} \\
\hline \multicolumn{10}{|c|}{ Object-control Skills } \\
\hline \multirow{3}{*}{$\begin{array}{l}\text { Age } \\
\text { Group }\end{array}$} & \multicolumn{5}{|c|}{ Percentile Frequency (\%) } & \multicolumn{4}{|c|}{ Raw Score } \\
\hline & \multirow{2}{*}{$<5$} & \multirow{2}{*}{5} & \multirow{2}{*}{$9-16$} & \multirow{2}{*}{$25-37$} & \multirow{2}{*}{$>50$} & São $P$ & & \multicolumn{2}{|c|}{ Normative (USA) } \\
\hline & & & & & & Girls & Boys & Girls & Boys \\
\hline 6 & 9.6 & 12.8 & 38.4 & 24.8 & 14.4 & $22-28$ & $27-33$ & $30-33$ & $36-41$ \\
\hline 8 & 32.0 & 17.2 & 38.6 & 9.8 & 2.4 & $28-31$ & $29-36$ & $39-40$ & 43-44 \\
\hline 10 & 29.4 & 24.3 & 34.6 & 9.6 & 2.1 & $30-34$ & $34-40$ & 42 & 44-45 \\
\hline Total & 23.7 & 18.3 & 37.0 & 14.6 & 6.4 & 22-34 & $27-40$ & $30-42$ & 36-45 \\
\hline
\end{tabular}

The comparative São Paulo/normative (USA) raw scores clearly indicate substandard motor competence for the children from São Paulo, relative to the normative data. Independent of age group or sex, the Brazilian children presented consistently lower raw scores in both the locomotor and object-control subtests. Figure 1 alternatively depicts the frequency of children whose motor competence was categorized as very poor, poor, below average, and average by age group based on the gross motor quotient. Most of the 6 -year-old children showed motor competence classified as poor and below average. Comparatively, most of the 8- and 10-year-old children showed motor competence classified as very poor and poor. 


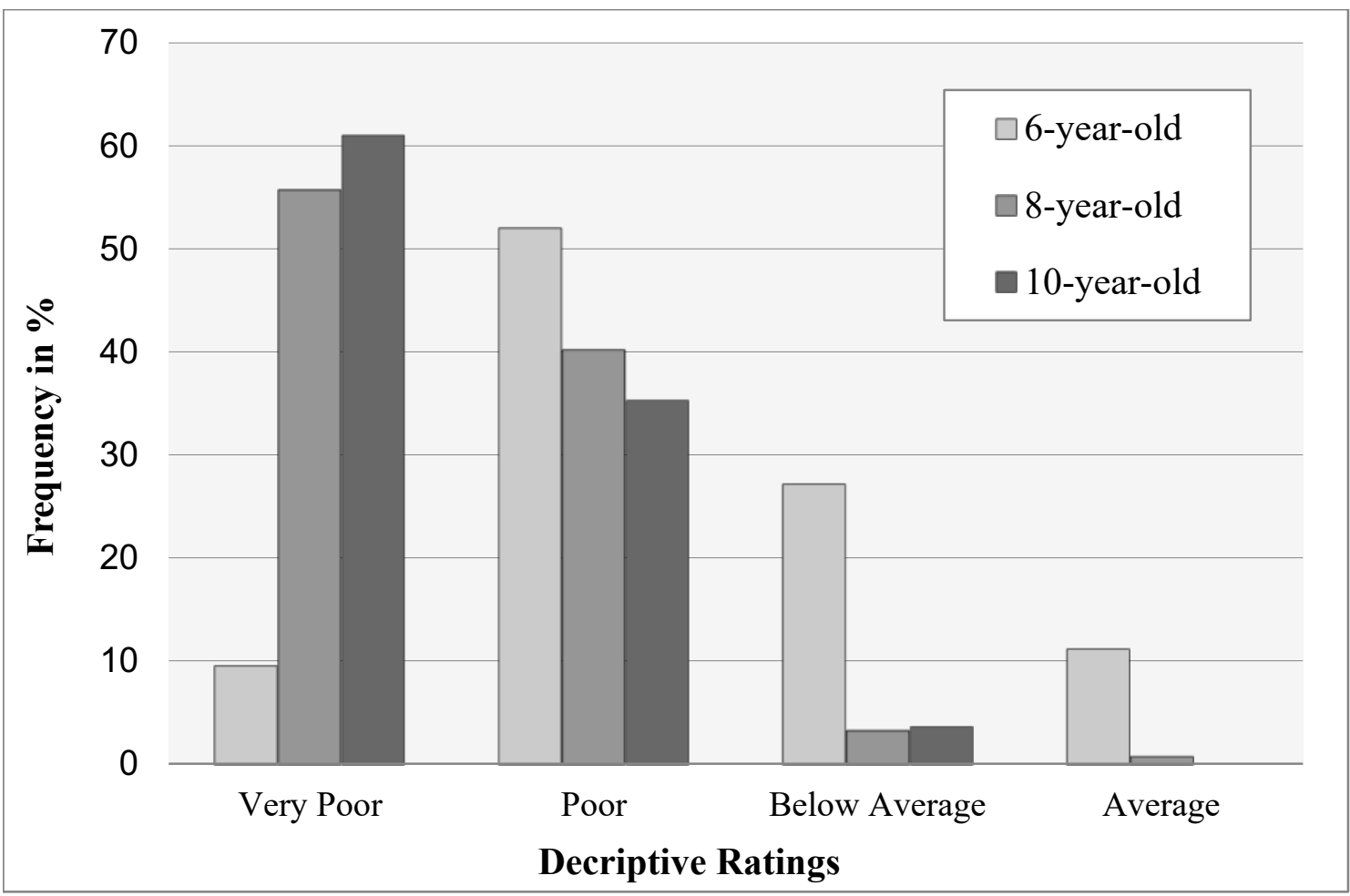

Figure 1.Motor competence of São Paulo children by age group based on the Test of Gross Motor Development-Second Edition (TGMD-2) gross motor quotient.

\section{DISCUSSION}

The purpose of this study was to directly assess FMS competence levels for children (ages 6, 8, and 10) from the city of São Paulo, Brazil. By pursuing this goal, we aimed to better understand the motor competence of Brazilian children and suggest potential factors affecting FMS competence levels. Consistent with international norms, our results showed that older children had higher FMS competence levels than younger children. However, raw scores from the TGMD-2 indicated that the children from São Paulo lagged behind age group peers in expected FMS competence levels, irrespective of sex. More importantly, our results showed that the deficit in FMS competence increases with chronological age. In general, children from São Paulo fell below the $15^{\text {th }}$ percentile of the normative TGMD-2 data, and their motor competence was classified as poor by the age of 6 and very poor by the ages of 8 and 10 .

Our first finding that older children had higher FMS competence levels than younger children is consistent with findings from several previous studies 13-15, 17, 18 . Therefore, we can conclude that children from São Paulo, Brazil follow the same general developmental track as children in other domestic and international locales. Specifically, our results showed that 10-year-old children were more competent than 8- and 6-year-old children when performing both locomotor and object-control skills and that 8-year-old children were more competent than 6-year-old children when performing object-control skills. 
More importantly, however, our results clearly showed that the motor equivalent age for the children from São Paulo was lower than their chronological age for all three age groups. These results are consistent with findings from previous Brazil-based studies 6 , 13,14 and confirm that children from São Paulo, as well as elsewhere in Brazil, do not reach the expected levels of FMS competence. The TGMD-2 normative data, which provided the basis for this finding, originated from a sample of North American children, raising questions regarding its applicability to Brazilian children. The applicability of the TGMD-2 for Brazilian children has, however, been previously validated ${ }^{19}$, minimizing any possible cultural issues that may affect the broader TGMD-2 results. Therefore, we can conclude that children from São Paulo have not adequately achieved FMS competence irrespective of sex, even by the age of 10 .

Several previous studies have purported that physical activity programs and physical education interventions at school may improve FMS competence in children 6, 17, 20. Providing some basis for this assertion, previous studies conducted in Brazil found that Brazilian children of different ages met expected FMS competence levels when adequately provided with quality motor experiences $6,17,20$. Similar and more marked improvements in FMS competence have been observed in other countries 16, 21, 22. Based on these collective findings, we can conclude that access to quality motor experiences, activities, and programs is essential to positively affect and shape FMS competence in children. The lower FMS competence levels observed in children from São Paulo may be attributable to a lack of access to an environment that adequately promotes FMS improvement.

In conjunction with other motor experiences and activities, physical education programs in schools should provide further opportunities for FMS improvement in young children. However, existing physical education programs, which are typically administered twice a week for $45 \mathrm{~min}$ on each day, often comprise only free play rather than any formal motor skill instruction. This lack of opportunity for structured practice of FMS and the corresponding information necessary to promote developmental changes towards competence in FMS ${ }^{3}$ was reflected in the lack of FMS competence in São Paulo children. These results suggest a pressing need to identify and implement actionable strategies to increase FMS competence in children through physical education programs from early in school.

Further exacerbating this need, the deficit in a child's FMS competence level increased with their chronological age. Our results clearly showed that the difference between equivalent motor age and chronological age was highest for 10-year-old children, with decreasing differences for 8- and 6-year-old children, respectively. This finding related to cumulative developmental delay reflects an important characteristic of motor development-previous acquisitions form the basis for subsequent new acquisitions ${ }^{3,14}$. Children from São Paulo exhibited cumulative developmental delays, lagging further behind their age peers as their chronological age advanced. Since ongoing participation in motor activities generally requires proficient performance 1,2 , this finding raises concerns regarding a child's competence and participation in motor activities as they age.

Based on the TGMD-2 normative data ${ }^{16}$, the highest concentrations of São Paulo children occurred in the lowest motor competence percentiles. Consistently, the majority of 6 -year-old children demonstrated motor competence classified as poor while the majority of 8- and 10-year-old children demonstrated motor competence classified as very poor. This deficit in FMS competence should motivate the future enrollment of these children in regular, recreational motor activities. A lack of FMS competence may prevent these

\begin{tabular}{l|l|l|l|ll}
\hline Avigo et al. & 2019 & VOL.13 & N.2 & https://doi.org/10.20338/bjmb.v13i2.128
\end{tabular}


children from acquiring and performing more challenging and specific skills required in sports, dance and rhythmical activities, martial arts, and many more. A child's lack of motor competence, particularly FMS competence, may determine their future motor activity participation. Previous studies have confirmed that FMS competence is one of the determinants for physical activity participation throughout life ${ }^{23,24}$. The motor competence deficit observed in São Paulo children, which increased with chronological age, may contribute to less active and sedentary lifestyles as they age.

Empirical studies have indicated that approximately half of all São Paulo children (with ages similar to this study's sample) are sedentary ${ }^{25}$. These statistics are alarming because participation in physical activity during childhood leads to higher participation in physical activity during adolescence, resulting in health and cognitive benefits 7,8 . Active and motor-competent individuals are more likely to become autonomous and also proficient in other domains and daily life activities ${ }^{7}$. Motor competence is thus important to acquire early in life. Unfortunately, this study's findings indicate that this is not the case for the children from São Paulo.

\section{LIMITATIONS}

This study is not without limitations. First, we did not attempt to identify or characterize the motor activities that São Paulo children experienced either in school or through extracurricular programs. Although this omission affected our ability to decisively recommend detailed FMS improvement strategies (because we do not fully understand what motor activities they have or are developing), it did not affect the study findings related to the motor competence deficit observed in São Paulo children.

Second, and as previously noted, the TGMD-2 normative data referenced in this study originated from a sample of North American children, raising questions regarding its applicability to Brazilian children. The applicability of the TGMD-2 for Brazilian children has, however, been previously validated ${ }^{19}$, minimizing any possible cultural issues that may affect the broader TGMD-2 results.

Finally, this cross-sectional study represents only a snapshot in time. A longitudinal study would provide more detailed information regarding a child's acquisition and mastering of FMS in São Paulo. Nonetheless, the findings from this cross-sectional study effectively confirmed and characterized the problem of motor competence deficit in children from Sao Paulo. Further research is required to fully understand the factors affecting motor competence levels in Sao Paulo children and to identify strategies for ensuring the health and well-being of children, not only in Sao Paulo but also across Brazil.

\section{IMPLICATIONS AND CONCLUSIONS}

The purpose of this study was to directly assess FMS competence levels for children (ages 6, 8, and 10) from the city of São Paulo, Brazil. By pursuing this goal, we aimed to better understand the motor competence of Brazilian children and identify potential factors affecting FMS competence levels. Test results indicated that children from São Paulo demonstrated low competence levels (below the $15^{\text {th }}$ percentile) across all FMS. Moreover, the observed motor competence deficit increased with age. Children's competence levels were classified as poor in 6-year-old children and very poor in 8- and

\begin{tabular}{l|l|l|l|ll}
\hline Avigo et al. & 2019 & VOL.13 & N.2 & https://doi.org/10.20338/bjmb.v13i2.128
\end{tabular}


10-year-old children. This developmental delay in motor competence may encourage children to adopt less active and more sedentary behaviors, preventing them from experiencing all of the health, social, and cognitive benefits that physical activity might provide. Providing sufficient opportunities for children to adequately develop motor competence would promote positive health trajectories in children.

The results of this study substantially contribute to the state of knowledge regarding FMS and broader motor competence in children. Two key findings from this study are that urban-area children in Brazil had lower overall FMS competence levels than their age peers and that this motor competence deficit increased with chronological age, indicating that the regular activities in which children are engaged do not adequately promote FMS competence. Instead, new and different approaches must be implemented to ensure that children engage in motor activities that promote FMS competence. In doing so, children will have the opportunity to remain engaged and even enjoy physical activity throughout their life.

\section{REFERENCES}

1. Logan S, Robinson L, Getchell N, Webster E, Liang L-Y, Golden D. Relationship Between Motor Competence and Physical Activity: A Systematic Review. Research Quarterly for Exercise and Sport. 2015;4(4):416-26.

2. Stodden DF,Goodway JD, Langendorfer SJ, Roberton MA, Rudisill ME, Garcia C, et al. A Developmental Perspective on the Role of Motor Skill Competence in Physical Activity: An Emergent Relationship. Quest. 2008;60(2):290-306.

3. Barela JA. Fundamental motor skill proficiency is necessary for children's motor activity inclusion. Motriz. 2013;19(3):548-51.

4. Newell KM. Constraints on the development of coordination. In: Wade MG, Whiting HTA, eds. Motor development in children: Aspects of coordination and control. Boston, MA: Martin Nighoff 1986:341-60.

5. Clark JE. On the problem of motor skill development. JOPERD. 2007;78(5):39-45.

6. Lemos AG, Avigo EL, Barela JA. Physical education in kindergarten promotes fundamental motor skill development. Advances in Physical Education. 2012;2(1):17-21.

7. Aberg MA, Pedersen NL, Toren K, Svartengren M, Backstrand B, Johnsson T, et al. Cardiovascular fitness is associated with cognition in young adulthood. Proceedings of the National Academy of Sciences of the United States of America. 2009 Dec 8;106(49):20906-11.

8. Malina RM, Little BB. Physical activity: the present in the context of the past. American Journal of Human Biology. 2008 Jul-Aug;20(4):373-91.

9. Seefeldt $\mathrm{V}$, Haubenstricker J. Patterns, phase, or stages: an analytical model for the study of developmental movement. In: Kelso JAS, Clark JE, eds. The Development of Movement Control and Coordination. New York: John Wiley \& Sons, Ltd 1982:309-18.

\begin{tabular}{l|l|l|l|ll}
\hline Avigo et al. & 2019 & VOL.13 & N.2 & https://doi.org/10.20338/bjmb.v13i2.128
\end{tabular}


10. Cattuzzo MT, Dos Santos Henrique R, Re AH, de Oliveira IS, Melo BM, de Sousa Moura $\mathrm{M}$, et al. Motor competence and health related physical fitness in youth: A systematic review. Journal of science and medicine in sport. 2015 Feb;19(2):123-9.

11. Lopes VP, Rodrigues LP, Maia JAR, Malina RM. Motor coordination as predictor of physical activity in childhood. Scandinavian Journal of Medicine \& Science in Sports. 2011;21:663-9.

12. Robinson LE, Stodden DF, Barnett LM, Lopes VP, Logan SW, Rodrigues LP, et al. Motor Competence and its Effect on Positive Developmental Trajectories of Health. Sports Medicine. 2015 Sep;45(9):1273-84.

13. Abiko RH, Caruzzo NM, Bim RH, Nazario PF, Vieira JLL. Avaliação do desempenho motor de crianças de 6 e 9 anos de idade. Cinergis. 2012;13(3):21-6.

14. Rodrigues D, Avigo EL, Barela JA. Proficiency of fundamental motor skills in children of a public school in the city of São Paulo. Brazilian Journal of Motor Behavior. 2015;9(1):1-9.

15. Spessato BC, Gabbard CP, Valentini N, Rudisill M. Gender differences in Brazilian children's fundamental movement skill performance. Early Child Development and Care. 2012;183(7):916-23.

16. Ulrich DA. Test of gross motor development. 2nd ed. Austin, TX: Pro-Ed 2000.

17. Cotrim JR, Lemos AG, Júnior JEN, Barela JA. Desenvolvimento de habilidades motoras fundamentais em crianças em diferentes contextos escolares. Revista da EducaçãoFísica/UEM. 2011;22(4):523-33.

18. Kim S, Kim MJ, Valentini NC, Clark JE. Validity and reliability of the TGMD-2 for South Korean children. Journal of Motor Behavior. 2014;46(5):351-6.

19. Valentini NC. Validity and reliability of the TGMD-2 for Brazilian children. Journal of Motor Behavior. 2012;44(4):275-80.

20. Araujo MP, Barela JA, Celestino ML, Barela AM. Contribution of different contents of physical education classes in elementary school I for the development of basic motor skills. RevistaBrasileira de Medicina e Esporte. 2012;18(3):153-7.

21. Bakhtiari S, Shafinia $P$, Ziaee V. Effects of selected exercises on elementary school third grade girl students' motor development. Asian Journal of Sports Medicine 2011 Mar;2(1):51-6.

22. Pang AWY, Fong DTP. Fundamental motor skill proficiency of Hong Kong children aged 69 years. Research in Sports Medicine. 2009;17:125-44.

23. Fisher A, Reilly JJ, Kelly LA, Montgomery C, Williamson A, Paton JY, et al. Fundamental movement skills and habitual physical activity in young children. Medicine and Science in Sports and Exercise. 2005;37(4):684-8.

24. Stodden DF, True LK, Langendorfer SJ, Gao Z. Associations among selected motor skills and health-related fitness: indirect evidence for Seefeldt's proficiency barrier in young adults? Research quarterly for exercise and sport. 2013 Sep;84(3):397-403.

25. IKS. The Infant and Kids Study. 2017 [cited; Available from: http://corporativo.nestle.com.br/historias/criancas-e-sobrepeso 
Brazilian Journal of Motor Behavior

\section{Research Article}

Citation:Avigo EL, Stodden DF, Silva AAR, Rodrigues VB, Barela JA.Motor competence deficit in urban-area Brazilian children based on chronological age. BJMB.2019: 13(2): 52-63.

Editor: Dr Fabio Augusto Barbieri - São Paulo State University (UNESP), Bauru, SP, Brazil; Dr Natalia Madalena

Rinaldi - Federal University of Espírito Santo (UFES), Vitória, ES, Brazil.Copyright: @ 2019 Avigo, Stodden, Silva,

Rodrigues and Barela and BJMB. This is an open-access article distributed under the terms of the Creative Commons

Attribution-NonCommercial-NoDerivatives 4.0 International License which permits unrestricted use, distribution, and reproduction in any medium, provided the original author and source are credited.

Funding: This study was supported by CAPES/PROSUP, Brazilian Federal Government.

Competing interests: The authors have declared that no competing interests exist.

DOI: $10.20338 /$ bjmb.v13i2.128 